\title{
Representação simbólica por crianças surdas na Educação Infantil
}

\author{
Beatriz Aparecida dos Reis Turetta* \\ Cristina Broglia Feitosa de Lacerda**
}

\begin{abstract}
Resumo
O interesse deste trabalho vincula-se ao atendimento educacional bilíngue oferecido a crianças surdas na Educação Infantil. Ancorados nos pressupostos da abordagem histórico-cultural entendemos que a aquisição da linguagem escrita se inicia bem antes do início do traçado das primeiras letras. Nesse sentido, realizamos uma pesquisa com o objetivo de encontrar os indícios do processo de desenvolvimento da linguagem escrita de crianças surdas que frequentam um Programa Inclusivo Bilíngue. A pesquisa foi realizada em uma sala multisseriada que atende crianças surdas na Educação Infantil com língua de instrução Libras. Para o presente relato são trazidos dados relativos a duas crianças que frequentavam a sala bilíngue durante o desenvolvimento do projeto "baú de histórias". Os dados evidenciam que os resultados alcançados nas representações simbólicas só foram possíveis devido a centralidade que a Libras ocupa na educação dessas crianças. A Libras tem proporcionado aumento significativo no repertório linguístico das crianças e consequentemente ampliado as possibilidades de significação e de desenvolvimento de modo geral.

Palavras-chave: Educação de surdos; Teoria Histórico-Cultural; Desenho infantil; Desenvolvimento da Linguagem; Educação Infantil.
\end{abstract}

\section{Symbolic representation by deaf children in Early Childhood Education}

\begin{abstract}
This work is related to the bilingual educational service offered to deaf children in Early Childhood Education. Based on historical-cultural approach assumptions, we understand that acquisition of written language begins even before the beginning of their first writting letters. In this sense, we have conducted a research aiming for finding development process evidences of written language of deaf children who attend an Inclusive Bilingual Program. The research happened at a multi-series class that serves deaf children in Early Childhood Education with Brasilian Sign Language (Libras) as instruction language. This report, discuss datas about two children who attended the bilingual class during development of a Project named "story chest". That datas show that the results on symbolic representations were only possible due to centrality of Libras in the education of these children. Libras has provided a significant increase in linguistic repertoire of those children and consequently expanded theis meaning possibilities and developments, in general.

Keywords: Deaf education; Historical-Cultural Theory; Childish drawing; language development; Childhood education.
\end{abstract}

\section{Introdução}

Ancorados na perspectiva histórico-cultural entendemos que o homem nasce um ser social e se desenvolve na relação com os outros (presentes, ausentes, elementos da cultura, entre outros). É na relação com os membros mais experientes da cultura e com as produções culturais produzidas pela humanidade que os novos membros têm a oportunidade de humanizar-se (VIGOTSKI, 1995).

Nessa perspectiva, assumimos que as possibilidades de desenvolvimento se encontram na vida social. Não se trata de ignorar déficits e deficiências do organismo, mas de acreditar que a plasticidade do funcionamento humano, a depender das condições criadas pelo grupo social, pode compensar as insuficiências orgânicas (VIGOTSKI, 1989).

\footnotetext{
*Endereço Eletrônico: biaturetta1@gmail.com
}

***Endereço Eletrônico: cbflacerda@gmail.com
No entanto, tornar-se humano é muito mais complexo do que simplesmente aprender os modos como a sociedade em que nasceu se organiza ou os conhecimentos que acumulou antes de seu nascimento. Nessa abordagem entendemos o desenvolvimento como um processo dialético de conversão das relações interpessoais em funcionamento intrapessoal (VIGOTSKI, 1995).

Antes mesmo de nascer, o bebezinho já está imerso em significações a respeito de sua chegada. Ao nascer o bebê não internaliza as relações sociais em si, mas as possibilidades de significação que elas lhe proporcionam.

Dizer que o que é internalizado é a significação dessas relações equivale a dizer que o que é internalizado é a significação que o outro da 
relação tem para o eu; o que, no movimento dialético da relação, dá ao eu as coordenadas para saber quem é ele, que posição social ocupa e o que se espera dele (PINO, 2000, p.66).

Nessa interpretação, o processo de tornar-se humano está estreitamente relacionado com as possibilidades de significação e de acesso as funções psíquicas superiores (atenção voluntária, memória, imaginação, linguagem e pensamento entre outras) num processo que não é linear e muito menos traçado por alguma linha evolutiva que pressuponha somente mudanças gradativas no decorrer do tempo. Trata-se de

um complexo processo dialético que se distingue por uma complicada periodicidade, a desproporção no desenvolvimento das diversas funções, a metamorfose ou transformação qualitativa de uma forma em outra, um complexo entrelaçamento de processos evolutivos e involutivos, um complexo cruzamento de fatores externos e internos, um complexo processo de superação de dificuldades e de adaptação (VIGOTSKI, 1995, p. 141).

Em suma, o desenvolvimento humano só pode ser entendido nessa abordagem como um processo dinâmico, que implica evolução, involução e revolução. As possibilidades de desenvolvimento encontram-se na vida social e a cada nova experiência, surgem novas oportunidades de constituir-se e de significar-se de modo diferente.

$O$ signo tem lugar de destaque nessa abordagem. É a linguagem verbal, considerada signo por excelência, que irá proporcionar as mudanças mais significativas na constituição do ser humano. A aquisição de uma língua tem papel fundante na formação e na tomada de consciência do homem. É pela língua que as relações se estabelecem, que se constroem os significados, que as novas gerações têm oportunidades de se apropriar das produções humanas de seus antepassados (GÓES, 2012).

A língua proporciona ampliação do campo perceptual, permite que o homem organize, guie, planeje e avalie seu próprio comportamento. Em outras palavras, é na e pela língua que nos constituímos humanos capazes de pensar e de expressar nosso pensamento. A língua transforma cada função em específico e, também, a relação entre elas, organizando e reorganizando a atenção, memória, pensamento etc., possibilitando a humanização de cada um.

Considerando que a escrita é uma representação da língua oral utilizada pela comunidade majoritária, este trabalho tem como objetivo encontrar indícios do processo de desenvolvimento da linguagem escrita de crianças surdas que iniciam seu contato com a Língua Brasileira de Sinais (Libras) e que precisarão escrever numa segunda língua, a Língua Portuguesa.

\section{O desenvolvimento de língua da criança surda}

Como destacado anteriormente, nessa abordagem teórica a língua ocupa lugar de destaque no desenvolvimento humano por ser considerada fundante dos processos psíquicos superiores (VIGOTSKI, 1995). Isso vale também para o caso das crianças com surdez, com a especificidade que para elas a língua que irá favorecer seu desenvolvimento pleno é a Libras (LODI; LACERDA, 2009; LACERDA; SANTOS; MARTINS, 2016).

Essa defesa, ainda que óbvia para familiares, amigos e profissionais que atuam junto à comunidade surda, se faz necessária na medida que nos dias atuais ainda há muita ignorância e desrespeito aos diferentes modos de ser e de viver que existem em nossa sociedade. Do mesmo modo em que as crianças ouvintes têm direito a adquirir uma língua de modo natural, até mesmo de forma inconsciente, na interação com seu grupo social e linguístico, as crianças surdas também o têm (BRASIL, 2002, 2005).

Elas só não o fazem como as crianças ouvintes porque a Língua Portuguesa nos primeiros anos de vida se materializa essencialmente na modalidade oral-auditiva. Considerando que existe um déficit auditivo das crianças surdas, essa modalidade de língua que depende da audição para se materializar fica inacessível a ela. Para que a criança surda tenha acesso a uma língua, a aquisição da mesma precisa passar por outras vias que não sejam as da audição.

Nessa direção, considerando que a Libras é uma língua que se materializa nas relações sociais na modalidade gesto-visual, de modo inteiramente independente do funcionamento da audição, acreditamos que é a única língua capaz de proporcionar às crianças surdas o mesmo que a Língua Portuguesa proporciona às crianças ouvintes. Crianças surdas que encontram parceiros usuários da Libras desde a mais tenra idade desenvolvem suas possibilidades linguísticas e, consequentemente, suas potencialidades de desenvolvimento de modo muito parecido com as crianças ouvintes falantes da Língua 
Portuguesa (LODI; LACERDA, 2009; LACERDA; SANTOS; MARTINS, 2016).

Pesquisas nacionais (LODI; LUCIANO, 2009; GÓES; BARBETTI, 2009; MOURA, 2013) e internacionais (GARCIA; KARNOPP, 2016) têm destacado a importância da aquisição precoce da língua de sinais para o desenvolvimento das crianças surdas. No Brasil é um desafio que permanece, dada a ausência de políticas públicas que assegurem efetivamente os direitos já previstos por lei (BRASIL, 2002, 2005) a essa clientela.

Considerando que as crianças surdas brasileiras vivem numa sociedade usuária da Língua Portuguesa, espera-se também que essas crianças se tornem bilíngues numa modalidade de bilinguismo sucessivo em que a criança adquire a Libras como primeira língua (L1) e a Língua Portuguesa na modalidade escrita como segunda língua (L2). Que tenham a Libras como língua de constituição e possam aprender a Língua Portuguesa na modalidade escrita para poderem circular em outros espaços e terem acesso as produções humanas/culturais disponíveis em Língua Portuguesa. Para além das discussões sobre a necessidade de maior circulação da Libras, da ausência de materiais em Libras e da aceitação da surdez como uma diferença, é imprescindível que a escola se responsabilize pela educação bilíngue dessas crianças.

\section{O desenvolvimento da representação simbólica escrita por crianças surdas}

Atualmente ainda que as escolas estejam se apropriando dos estudos sobre práticas de letramento, percebe-se no cotidiano que o ensino da leitura e escrita ainda está muito voltado para o ensino do traçado de letras, da união das mesmas para a formação de sílabas, que formam palavras, frases e textos, enfim voltado para as técnicas de alfabetização.

De acordo com a perspectiva que adotamos os processos de representação simbólica rumo a aquisição da escrita percorrem outros caminhos que não apenas estes. Assim como todas as demais funções psíquicas superiores, a escrita é um processo que está muito relacionado com a construção do simbolismo na criança. $\mathrm{O}$ gesto, o faz de conta e o desenho são elementos essenciais dessa construção e são considerados nessa abordagem essenciais para o entendimento do funcionamento da escrita.

Para ler e escrever entendemos que seja necessário brincar e desenhar. Isso porque, brincar e desenhar são passos importantes considerados nessa perspectiva como a pré-história da linguagem escrita (VIGOTSKI, 1984).

É a partir da brincadeira, especialmente a de faz-de-conta que as crianças terão as primeiras possibilidades de lidar com a representação e com o simbólico. Crianças muito pequenas experimentam os brinquedos, colocam na boca, apertam, batem, giram, exploram todos os ângulos. Com o passar do tempo e da qualidade das experiências criadas pelo grupo social elas podem tornar-se capazes de utilizar esses objetos como se fossem outros. Assim, no âmbito do imaginário, um cabo de vassoura vira um cavalo, uma caneta vira varinha mágica, uma caixa de papelão permite um passeio pelos planetas. Nesses casos, são as relações interpessoais que irão determinar a continuidade ou não das brincadeiras. Geralmente, a presença da linguagem é determinante para que a brincadeira de faz-de-conta evolua para os jogos de papéis (COSTA; SILVA; SOUZA, 2013). Ao combinar que Maria é a mãe e que João vai ser o pai as crianças estabelecem um roteiro, organizam e guiam a ação, saem do real perceptível para operar com representações da realidade. Esse é um salto importante para o desenvolvimento da imaginação, do pensamento e posteriormente da escrita (LACERDA, 1995).

Com relação ao desenho acontece algo semelhante. Inicialmente, não é incomum que a criança experimente os objetos, mastigue o lápis, coma a borracha, acabe com o giz de cera. A presença de membros mais experientes da cultura e a interação com as diferentes formas de expressão vão dando indícios para as crianças que aqueles objetos geralmente são utilizados para desenhar, pintar, escrever, apagar. E aí a criança passa a tentar reproduzir ou representar coisas. No início são apenas garatujas incompreensíveis se não estiverem acompanhadas da fala. Nesses casos a presença do outro é ainda mais importante para favorecer esses processos de significação. A partir do momento que a criança percebe que seu traçado pode significar algo, ela passa a experimentar traçados que sejam mais compreensíveis para o outro. Passa da experimentação dos objetos para a tentativa de representação das coisas (VIGOTSKI, 1984).

Inicialmente a criança desenha o que conhece e diz: 'Essa é a minha mãe', referindo-se a um traçado qualquer. $\mathrm{O}$ salto de qualidade acontece quando a criança percebe o desenho como uma representação da sua mãe, não é sua mãe, mas sim uma representação da mesma. A participação do outro, membro mais experiente da cultura é de grande importância nesse processo. As crianças 
precisam de ajuda para perceberem que seus traçados podem ser utilizados para dizer coisas, expressar sentimentos, dar recados (VIGOTSKI, 1984).

$\mathrm{O}$ grande salto para a escrita acontece quando a criança percebe que pode desenhar coisas ou palavras. A partir do momento em que a criança descobre que a escrita é uma representação da língua utilizada, a maior necessidade é que a mesma faça sentido, seja tratada como algo importante e necessário para a vida (VIGOTSKI, 1984).

Mas a aquisição da linguagem escrita por crianças surdas é um desafio que envolve outras questões muito específicas se comparada a aquisição realizada por crianças ouvintes. As crianças ouvintes estão em contato com os sentidos e significações da Língua Portuguesa desde o nascimento, seu processo de letramento nessa língua acontece bem antes do momento em que se inicia seu processo de alfabetização. Elas conversam, pensam, brincam, desenham, leem e escrevem tudo numa mesma língua.

Para que as crianças surdas tenham acesso ao patrimônio cultural do grupo no qual estão inseridas, precisarão se constituir em duas línguas. Provavelmente essas crianças vão iniciar seu desenvolvimento da escrita brincando e desenhando com bases linguísticas da Libras, mas pouco a pouco evoluir em relação à escrita irão precisar dominar uma segunda língua: a Língua Portuguesa.

No caso das crianças surdas,

É a língua de sinais, como primeira língua (L1), que deve ser tomada como meio de mediação simbólica, base para a compreensão e significação dos processos sócio-históricoculturais e ideológicos da segunda língua (L2) (FORMAGIO; LACERDA, 2016, p.179).

Para que essas crianças tenham acesso e domínio da Língua Portuguesa na modalidade escrita de forma exitosa, deverão estar em ambientes em que o trabalho tenha centralidade na Libras, língua de construção conceitual que servirá de base para o aprendizado da Língua Portuguesa, de tal modo que ambas as línguas possuam prestígio e função no espaço escolar.

Outro aspecto importante da aprendizagem da Língua Portuguesa, que não pode passar despercebido pelos professores, é o fato de que a criança surda não irá se alfabetizar pelos métodos tradicionais que privilegiam as propriedades fonéticas das palavras. $\mathrm{O}$ ensino da leitura e escrita deverá passar necessariamente pela visualidade, é pela memorização das palavras que as crianças irão iniciar seu processo de aprendizagem da Língua
Portuguesa (FERNANDES, 2006).

Assim, é fundamental criar oportunidades para que a criança surda signifique a linguagem escrita e seus diversos usos a partir da Libras. Para isso, necessitam conhecer o processo de significação e construção de sentidos na Libras, para a partir deles criar processos de significação em Língua Portuguesa. Além disso, é importante levar em consideração que são as práticas de leitura aquelas que favorecem o desenvolvimento de linguagem e os processos de ensino-aprendizagem, uma vez que as práticas de leitura se estruturam em atividades que privilegiam aspectos visuais da língua. Atividades com estas ênfases favorecem que as diversas esferas simbólicas sejam acionadas para propiciar a construção de novos conhecimentos (LODI; LUCIANO, 2009).

\section{Considerações metodológicas}

Com o intuito de encontrar indícios do processo de desenvolvimento da linguagem escrita pelas crianças surdas, produções escritas dos sujeitos participantes do estudo foram analisadas a partir da abordagem microgenética, tal como proposto por Góes (2000), com base nas proposições de Vigotski (1984), com um olhar mais atento para as produções que pudessem indicar a gênese das futuras produções escritas dos sujeitos investigados.

Os dados fazem parte do material coletado pela primeira autora durante o período que esteve em pós-doutoramento. Os registros abrangem dados de situações imaginárias e de produções simbólicas. Os procedimentos abrangeram observação, videogravação, registro fotográfico das atividades e registro em diário de campo do cotidiano escolar.

O projeto "baú de histórias" teve a duração de um ano e o recorte aqui apresentado "A primavera da lagarta" foi desenvolvido durante dois meses letivos. Nesse período, a sala multisseriada atendia somente os dois alunos que são sujeitos dessa pesquisa: Laura e Felipe.

Laura tem 6 anos e participa do Programa Inclusivo Bilíngue a um ano. Antes disso nunca havia frequentado escola. Possui diagnóstico de surdez profunda bilateral e seu primeiro contato com a Libras foi nesse Programa.

Felipe tem 4 anos e participa do Programa Inclusivo Bilíngue a alguns meses. Antes disso frequentava outra escola de Educação Infantil sem acesso a Libras. Possui diagnóstico de surdez moderada-severa bilateral e seu primeiro contato com a Libras foi nesse Programa. 


\section{Contexto da pesquisa}

O estudo foi desenvolvido numa escola de Educação Infantil de um município de médio porte do interior do Estado de São Paulo. Essa escola possui parceria com a Universidade local para implementação de iniciativas que visam assegurar educação bilíngue para os alunos surdos da cidade ${ }^{i}$.

Atualmente o Programa Inclusivo Bilíngue está concentrado em duas escolas, uma de Educação Infantil (EI) e outra de Ensino Fundamental (EF) ${ }^{\mathrm{ii}}$. Os alunos surdos têm aulas em salas nas quais a Libras é a língua de instrução $0^{\mathrm{iii}}$, com professoras bilíngues, e tanto na EI como no EF até o quinto ano são organizadas salas multisseriadas, devido ao número reduzido de alunos surdos. A partir do sexto ano passam a frequentar salas nas quais a língua portuguesa é a língua de instrução, acompanhados de um intérprete de Libras. Todavia, para a disciplina de língua portuguesa, o intérprete não está presente, já que esta é oferecida como L2 por uma professora bilíngue, em consonância com a legislação vigente (BRASIL, 2005).

Além dessa organização, diariamente os alunos da EI participam de oficinas de Libras com uma instrutora surda que tem proporcionado momentos importantes de aprendizado da Libras. Nessas oficinas, os alunos surdos têm oportunidades de encontrar seus pares, ter contato com diferentes interlocutores de diversas idades, discutir aspectos da língua e da surdez, situações importantes tanto para a aquisição de língua quanto para a construção/internalização de uma imagem positiva de si mesmos.

$\mathrm{O}$ fato das escolas de EI e EF estarem localizadas uma ao lado da outra facilita que diferentes ações também aconteçam no cotidiano escolar, como feiras do conhecimento, momentos de brincadeiras coletivas, produção de materiais em Libras entre outras atividades.

Outra característica importante desse programa é a possibilidade que as famílias têm de aprender Libras na escola. Os grupos de famílias se reúnem semanalmente com o intuito de discutir as questões cotidianas que enfrentam com seus entes surdos e também para aprender a Libras. Paralelamente ao grupo de família são oferecidas oficinas de Libras para professores, funcionários e comunidade externa.

A parceria entre a prefeitura e a Universidade tem favorecido a implementação das propostas e a formação continuada de todos os profissionais envolvidos no programa sempre com o intuito de proporcionar melhorias na qualidade do atendimento das crianças surdas do município.

\section{A Educação Infantil Bilíngue}

Nesse programa a Educação Infantil tem dois grandes objetivos para a criança surda: proporcionar aquisição da Libras (com foco nas narrativas e nas atividades de brincadeira - especialmente a de faz-deconta por ser a atividade mais significativa da infância), e criar condições para a aquisição da Língua Portuguesa na modalidade escrita (com foco na produção de desenhos, considerado na perspectiva histórico-cultural como uma das atividades precursoras da aquisição da linguagem escrita mais propriamente dita).

O trabalho é realizado a partir de projetos interdisciplinares em que todos os conteúdos se interrelacionam a partir de uma temática. Durante o ano em que a pesquisa foi realizada, a professora estava trabalhando com o projeto "baú de histórias". Para esse relato são trazidos dados relativos ao trabalho desenvolvido com o livro "A primavera da lagarta" (ROCHA, 2011) com o objetivo de encontrar indícios do processo de desenvolvimento da linguagem escrita pelas crianças surdas.

\section{O projeto "A primavera da lagarta"}

O projeto desenvolvido a partir do livro "A primavera da lagarta" teve a duração de três meses. A primeira ação foi a contação da história em Libras de diversas maneiras, por diferentes narradores. A professora bilíngue, a instrutora surda e crianças surdas do EF narraram para Laura e Felipe, cada qual a seu modo, a história que estava sendo trabalhada. Foram criadas várias oportunidades de contação de história, a partir de diversos interlocutores. Em seguida, as próprias crianças produziram uma narrativa em Libras, que foi registrada em vídeo, e por isso pode ser vista e revista para que pudessem aprimorar seus modos de narrar, e pudessem refletir sobre sua narrativa. Além disso, as crianças tiveram a oportunidade de fazer uma atividade de dramatização, na qual puderam experimentar representar os diversos personagens da história.

Para além das narrativas em Libras, o trabalho pedagógico proporcionou também acesso ao tema 'ciclo de vida das borboletas' por meio de vídeos, fotos e outros livros de literatura que abordam a mesma temática. As crianças foram convidadas a representar o 'ciclo de vida das borboletas' a partir de diversos materiais, com 
diferentes propostas: massa de modelar, tinta, caixas de papel, recortes, materiais reciclados entre outras atividades. Algumas das atividades propostas pela professora bilíngue e realizadas por Laura e Felipe podem ser vistas nas Figuras 1 e 2.

FIGURA 1: Produções de Laura.
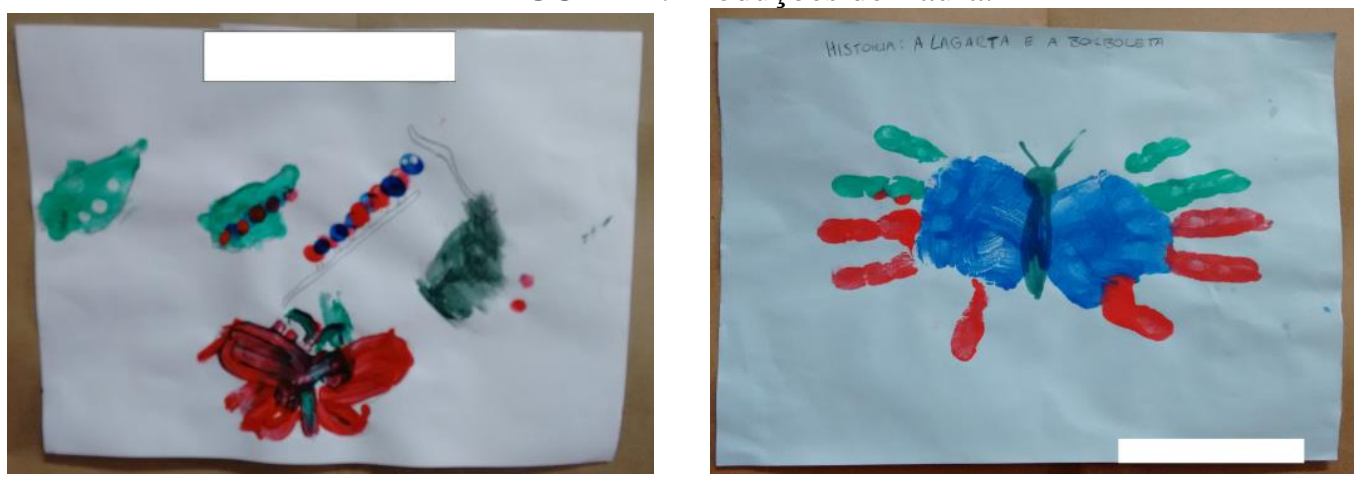

Fonte: Elaboração própria.

FIGURA 2: Produções de Felipe.
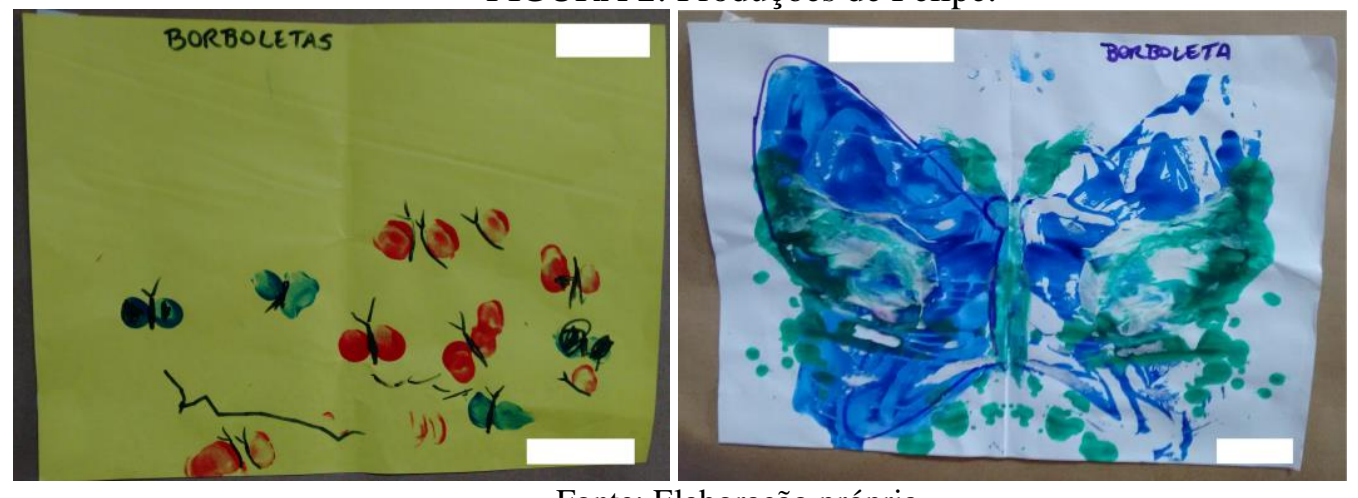

Fonte: Elaboração própria.

Além da produção de cada criança, a professora incentivava produções coletivas, e construía juntamente com seus alunos formas de representar conteúdos trazidos pela história. $\mathrm{Na}$ figura 3 vemos um exemplo de produção apoiada em imagens organizada pelos alunos com a ajuda da professora bilíngue.

\section{FIGURA 3: Produção coletiva.}

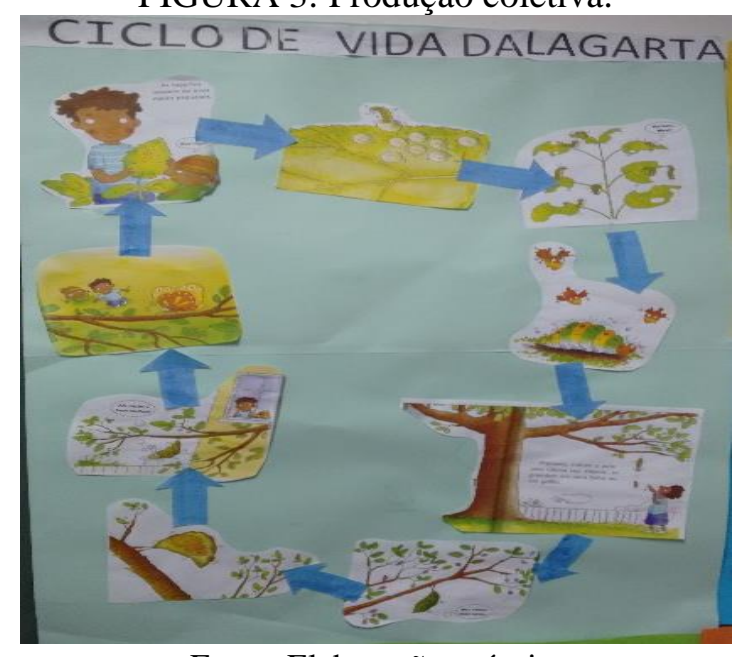

Fonte: Elaboração própria. 
Com o intuito de ampliar a percepção das crianças sobre as diferentes possibilidades de expressão foram trabalhadas algumas imagens de obras de arte com destaque para: Pinturas: Butterfly II, de Romero Brito; Borboletas Gigantes, de Salvador Dalí; Escultura em aço: Holocausto, de David Kracov; Fotografia: Borboletas Monarcas, da
National Geografic e Recorte e Colagem: Butterfly, de Rebecca J. Cole. Algumas imagens chamaram mais a atenção das crianças que outras, e então a professora pode explorar algumas delas propondo uma releitura. A figura 4 mostra a imagem da obra de Rebecca J. Cole, e a figura 5 a releitura realizada pela turma.

FIGURA 4: Butterfly de Rebecca J. Cole.

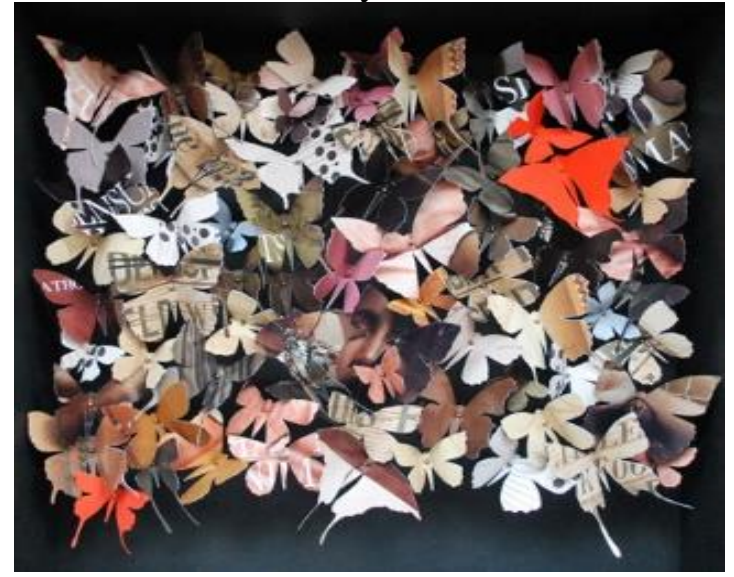

Fonte: http://www.rebeccajcoles.co.uk/

FIGURA 5: Borboletas - produção coletiva dos alunos e professora bilíngue.

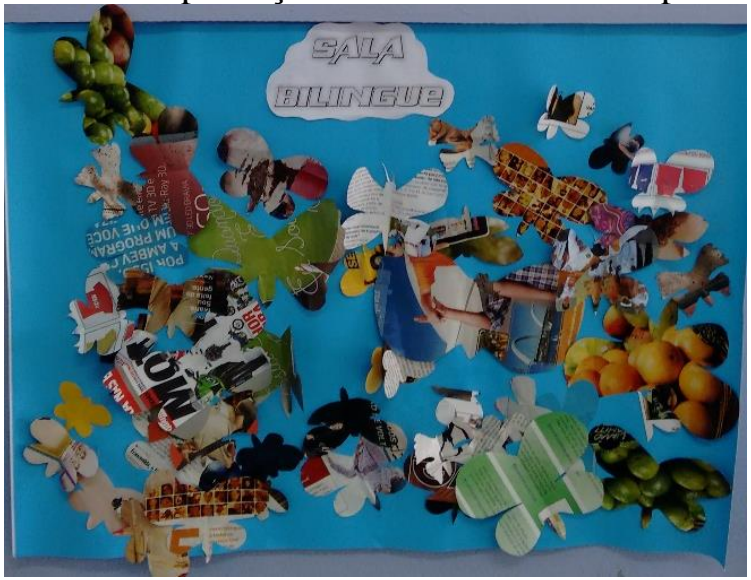

Fonte: Elaboração própria.

Ainda com o objetivo de que as crianças pudessem compreender que cada pessoa tem uma maneira própria de expressar-se, as famílias e pessoas próximas a elas foram convidadas a participar do projeto enviando para a escola desenhos feitos por elas mesmas de borboletas. Ao mesmo tempo em que as crianças conheciam obras reconhecidas mundialmente, entravam em contato com produções de pessoas muito próximas, podendo refletir sobre diferentes formas de representar as borboletas e seu ciclo de vida.

Ao final do projeto as crianças fizeram uma exposição de seus trabalhos. A exposição foi visitada por outros alunos da escola, pelos demais profissionais do Programa Inclusivo Bilíngue e pelos familiares.

\section{Discussão}

Com destacado anteriormente, nesta oportunidade, procuramos indícios do processo de desenvolvimento da linguagem escrita das crianças surdas que frequentam o Programa Inclusivo Bilíngue. Para atender esse objetivo, optamos por analisar mais detalhadamente as produções simbólicas de Felipe que começa a apresentar uma 
evolução em suas produções. Os desenhos de Felipe (Figura 6) que apresentamos foram realizados durante a última semana de trabalho do projeto "A primavera da lagarta".

\section{FIGURA 6: Desenho livre produzido por Felipe.}

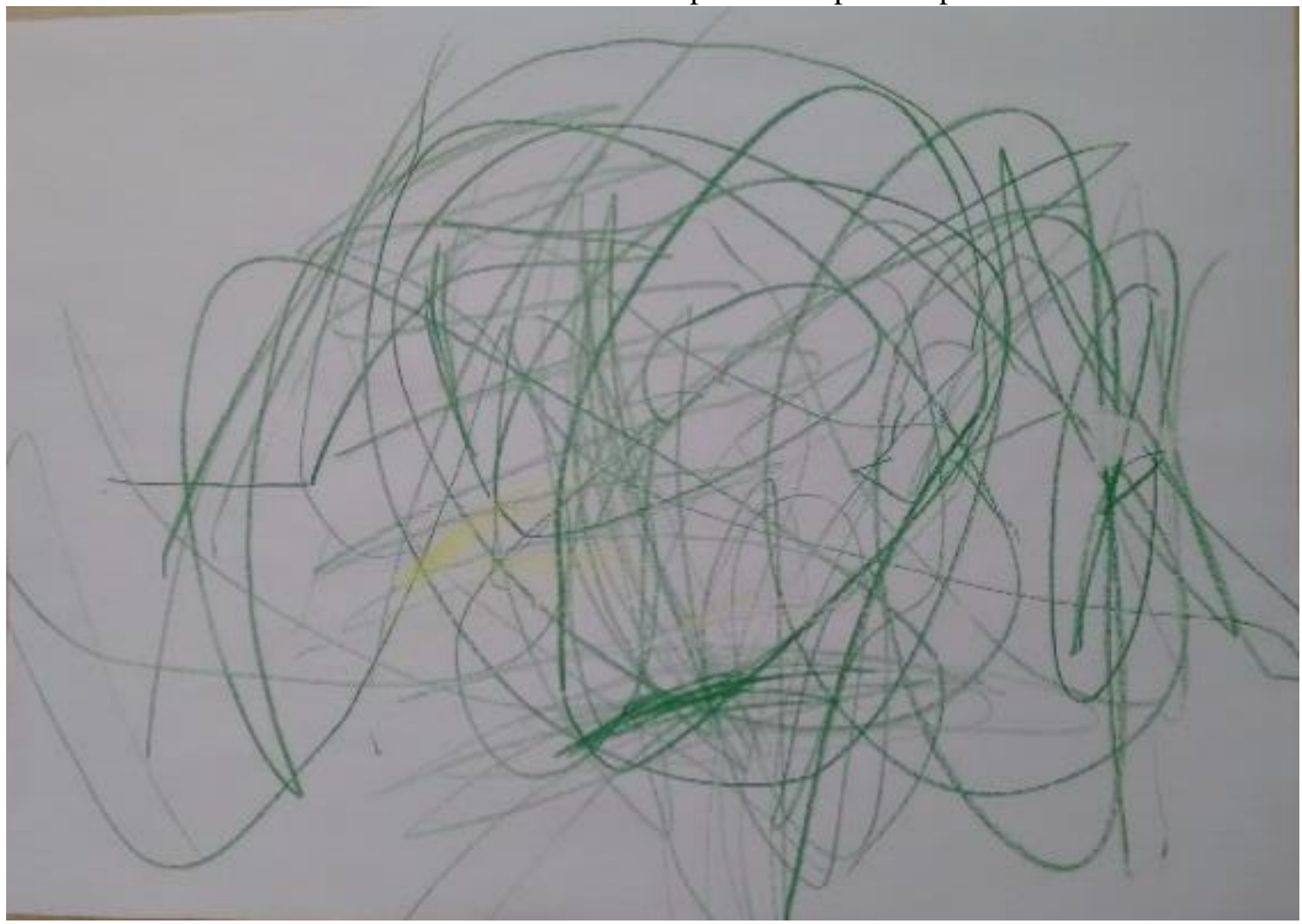

Fonte: Elaboração própria.

No dia em que Felipe realizou esse desenho a proposta da professora era que ele desenhasse o que quisesse. Felipe não se deteve por muito tempo na atividade. Parece-nos que estava mais interessado em acabar logo para poder brincar. No entanto, algumas considerações precisam ser tecidas a respeito dessas crianças que chegam a escola na Educação Infantil sem terem adquirido língua alguma.

Felipe entrou em contato com a Libras a partir do momento em que entrou na escola, ou seja, há aproximadamente seis meses. Antes disso Felipe frequentou outra escola de Educação Infantil sem nenhuma adaptação para sua condição de surdez. A família é ouvinte e também iniciou o contato com a Libras recentemente. Seu caso é muito parecido com o caso da maioria das crianças surdas desse país.

$\mathrm{O}$ atraso no desenvolvimento de língua compromete suas possibilidades de significação. $\mathrm{O}$ trabalho é árduo, ao mesmo tempo que essas crianças estão em fase de aquisição de uma língua, já estão enfrentando a dificuldade de tentar representá-la, algo bastante complexo a depender das propostas educacionais.

A escola que Felipe frequenta tem professores que compreendem suas necessidades, priorizam a Libras e estão o tempo todo procurando a melhor forma de alavancar o desenvolvimento dele e de seus companheiros de turma. Ainda que Felipe não esteja alcançando os mesmos resultados que comumente as crianças ouvintes alcançam nessa idade, seus progressos são extremamente significativos.

O trabalho desenvolvido por projetos tem trazido alguns resultados que podem ser comemorados, já que, crianças como Felipe, ainda em fase de aquisição de língua tem conseguido compreender as diversas possibilidades de expressão em Libras, além de formas de expressão artísticas.

$\mathrm{Na}$ Figura 7 temos o desenho de Felipe, resultado de uma atividade realizada que tinha como objetivo a representação de uma borboleta, pertinente ao tema que vinha sendo trabalhado a algum tempo com as crianças. 
FIGURA 7: Desenho de Borboleta de Felipe.

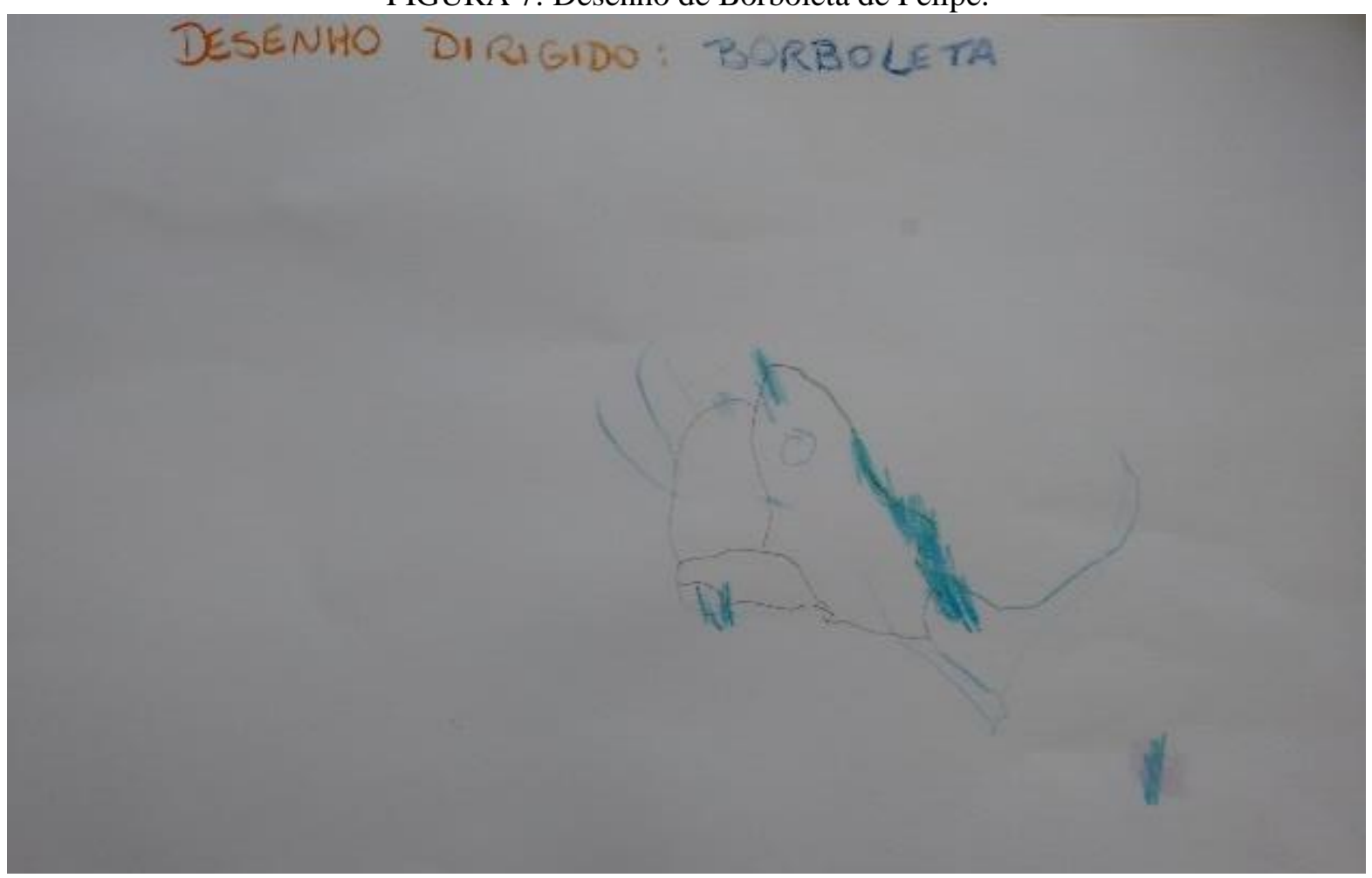

Fonte: Elaboração própria.

Conforme dito anteriormente, esse desenho foi realizado na última semana de aula do projeto. Antes disso Felipe já tinha tido contato com diferentes versões da história de vida da borboleta, narradas por diferentes interlocutores, inclusive participado de narrativas e dramatizações que lhe possibilitaram a construção de sentidos e significados a respeito do tema. Felipe produziu narrativas em Libras (ainda que bem simples) e teve contato com inúmeras possibilidades de expressões artísticas. Assistiu vídeos, viu fotos e obras de arte além de realizar atividades com a palavra borboleta em Língua Portuguesa na modalidade escrita.

Assim como no estudo de Zerbato e Lacerda (2015), o trabalho realizado com centralidade na Libras e com experiências em que as crianças tenham oportunidades de conhecer diferentes formas de representação, proporcionou a Felipe a ampliação tanto do conhecimento a respeito da vida das borboletas como das possibilidades de representá-la.

O conhecimento construído a partir das brincadeiras, dos vídeos, das imagens e das narrativas em Libras foram essenciais para a produção desse desenho. Ainda com um domínio emergente em Libras, enquanto sistema linguístico capaz de expressar seu pensamento, Felipe tem também a possibilidade de se expressar pelo desenho. Nessa atividade, seu desenho atinge sua função enquanto produção simbólica que antecede a escrita, ou seja, pelo desenho Felipe é capaz de representar aspectos de seu conhecimento acerca da temática e das características das borboletas.

Os desenhos de Felipe são representativos de seu processo de desenvolvimento. Na mesma semana em que ainda produz garatujas, é capaz de elaborar um desenho figurativo, com intenção de representação simbólica de seu pensamento, permitindo maior interpretação por parte de seu interlocutor.

Como afirmamos anteriormente, o processo de desenvolvimento está estreitamente relacionado com as possibilidades de significação e de acesso as funções psíquicas superiores. Podemos afirmar que Felipe é capaz de desenhar uma borboleta porque possui um repertório linguístico e de pensamento (percepção, atenção, memória e imaginação também) que lhe permitem materializar em uma produção seu aprendizado sobre as borboletas.

Não podemos afirmar o mesmo com relação a outras temáticas ainda não trabalhadas na escola. Considerando que Felipe só interage por meio de uma língua acessível a ele na escola, seu repertório linguístico é bastante restrito. Ainda que ele possa ter tido pouco interesse em representar na atividade de 
desenho livre, podemos considerar o fato que estando livre para representar ele tenha muito pouco a dizer.

Nosso interesse nesse trabalho esteve em encontrar os indícios do processo de desenvolvimento da representação simbólica pelas crianças surdas. Nosso olhar esteve voltado para as produções dos alunos e para os desenhos de Felipe com o intuito de encontrar as produções que estivessem relacionadas a trajetória que leva à linguagem escrita por essas crianças.

O desenho de Felipe dá indícios desse percurso. Faz parte da gênese de suas produções gráficas, na direção da aquisição da escrita que é muito anterior a produção dos desenhos, perpassado inicialmente pelo gesto e pela atividade do faz-deconta, mas implicado nas representações gráficas que com certeza são parte importante dessa trajetória.

\section{Considerações Finais}

Ao mesmo tempo que a representação de borboleta de Felipe nos indica que o trabalho realizado com as crianças surdas tem surtido efeitos significativos em seus processos de desenvolvimento, seu desenho livre nos aponta o tamanho do desafio que enfrentam no dia-a-dia.

$\mathrm{O}$ projeto desenvolvido com o livro "A primavera da lagarta" dá visibilidade para todo um trabalho que vem sendo pensado e discutido a muitas mãos. A parceria entre a universidade local e os profissionais que atuam no programa bilíngue tem proporcionado avanços significativos na qualidade de ensino dessas crianças.

Os professores têm transformado suas posturas, repensado suas ações, construído novas estratégias que contribuem para a melhoria do trabalho numa perspectiva que visa a interdisciplinaridade. Os resultados indicam que estão no caminho certo, mas que a responsabilidade frente aos desafios de tornar essas crianças bilíngues é grande. Eles têm conseguido utilizar as reuniões de equipe para integrar os conhecimentos e trocar experiências a respeito das temáticas elegidas; levam para as salas de aula a história dos conteúdos e sua contextualização; trabalham em parceria; estão criando o hábito de pesquisa; tem consciência política e pedagógica da importância do trabalho que realizam especialmente no que diz respeito a realidade da surdez e do tipo de sujeito que querem formar; realizam o planejamento de modo cuidadoso, estimulando a iniciativa, a criatividade, a cooperação e a corresponsabilidade; fatores que segundo Andrade (s/d) são algumas das características básicas da prática pedagógica interdisciplinar.

Destaca-se ainda que com um trabalho centrado na Libras, as crianças têm aumentado significativamente seu repertório linguístico e consequentemente têm ampliado suas possibilidades de significação e desenvolvimento de modo geral. O registro das atividades em Libras e em Língua Portuguesa tem favorecido a avaliação continuada tanto da evolução das crianças quanto dos desafios a serem enfrentados pelos profissionais.

Embora não seja intuito deste trabalho a análise das produções em Libras das crianças, cabe salientar que os resultados alcançados nas representações simbólicas só foram possíveis devido a centralidade que a Libras ocupa na educação dessas crianças. Os processos de significação foram todos construídos a partir do trabalho com imagens tendo a Libras como língua de instrução.

\section{Notas}

1 As iniciativas de pesquisa nesta unidade escolar têm recebido apoio de agências de fomento, a saber: Proc. CNPq 443756/2015-5; Proc. FAPESP 2012/17730-9.

$2 \mathrm{Na}$ escola de Ensino Fundamental também é oferecida a EJA para pessoas surdas que se interessem.

3 Língua de instrução é a língua utilizada pelo professor em todas as situações de ensino e interação com os alunos no cotidiano escolar.

\section{Referências}

ANDRADE, R. C. Interdisciplinaridade: Um novo paradigma curricular. Disponível em: <http://www.ufpa.br/ensinofts/interdisci.html>. Acesso em 17/08/2017.

BRASIL. Lei $n .^{\circ} 10.436$, de 24 de abril de 2002. Dispões sobre a Língua Brasileira de Sinais LIBRAS e dá outras providências. Diário Oficial [da] República Federativa do Brasil, Brasília, 24 de abril de 2002.

. Decreto $n^{\circ}$ 5.626. Regulamenta a Lei n. 10.436 , de 24 de abril de 2002, que dispõe sobre a Língua Brasileira de Sinais - Libras, e o artigo. 18 da Lei n. 10.098, de 19 de dezembro de 2000. Publicada no Diário Oficial em 22 de dezembro de 2005. 
COSTA, M. T. M. S.; SILVA, D. N. H.; SOUZA, F. F. Corpo, atividade criadora e letramento. 1. ed. São Paulo: Summus, 2013.

FERNANDES, S. F. Práticas de letramentos na educação bilíngue para surdos. Curitiba: CEED, 2006.

FORMAGIO, C. L. S.; LACERDA, C. B. F. Práticas pedagógicas do ensino de português como segunda língua para alunos surdos no Ensino Fundamental. In: LACERDA, C. B. F.; SANTOS, L. F.; MARTINS, V. R. O. (Orgs.). Escola e Diferença: caminhos para educação bilíngue de surdos. São Carlos: EdUFSCar, 2016. p. 169- 197.

GARCIA, B. G.; KARNOPP, L. B. (Orgs.). Change and Promise: Bilingual Deaf Education and Deaf Culture in LatinAmerica. 1. ed. Washington: Gallaudet University, 2016.

GÓES, M. C. R. A abordagem microgenética na matriz histórico-cultural: uma perspectiva para o estudo da constituição da subjetividade. Caderno $C E D E S$, v. 20, n. 50, 2000. p. 9-25. Linguagem, surdez e educação. Editora Autores Associados, 2012.

GÓES, M. C. R.; BARBETI, R. S. As interações da criança surda no espaço do recreio e sua formação bilíngue. In: LODI, A. C. B; LACERDA, C. B. F. (Orgs.). Uma escola duas línguas: letramento em língua portuguesa e língua de sinais nas etapas iniciais de escolarização. 4. ed. Porto Alegre: Editora Mediação, 2009, p. 127-141.

LACERDA, C. B. F. Inter-relação entre oralidade, desenho e escrita: o processo de construção do conhecimento. São Paulo: Cabral, 1995.

LACERDA, C. B. F.; SANTOS, L. F. MARTINS, V. R. O. Escola e diferença: caminhos para educação bilíngue de surdos. São Carlos: Edufscar, 2016.

LODI, A. C. B.; LACERDA, C. B. F. (Orgs.). Uma escola, duas línguas: letramento em língua portuguesa e língua de sinais nas etapas iniciais de escolarização. Porto Alegre: Mediação, 2009.

LODI, A. C. B; LUCIANO, R. T.

Desenvolvimento da linguagem de crianças surdas em língua brasileira de sinais. In: LACERDA, C. B. F.; LODI, A. C. B. Uma escola duas línguas: letramento em língua portuguesa e língua de sinais nas etapas iniciais de escolarização. Porto Alegre: Mediação, 2009. p. 33-50.

LURIA, A. R. O desenvolvimento da escrita na criança. In: VYGOTSKY, L. S.; LURIA, A. R.; LEONTIEV, A. N. Linguagem, desenvolvimento e aprendizagem. São Paulo: Ícone/Edusp, 2001. p.143-189.

MOURA, M. C. Surdez e Linguagem. In: LACERDA, C. B. F.; SANTOS, L. F. (Orgs.). Tenho um aluno surdo, e agora? Introdução à Libras e educação de surdos. São Carlos, SP: EDUFSCar, 2013. p. 13-26.

PINO, A. O social e o cultural na obra de Lev Vigotski. Educação \& Sociedade, Campinas, Cedes, 71, 2000.

ROCHA, R. A primavera da lagarta. São Paulo: Salamandra, 2011.

VYGOTSKI, L. S. A formação social da mente: o desenvolvimento dos processos psicológicos superiores. São Paulo: Martins Fontes, 1984.

Fundamentos de defectología. Obras

Completas. v. 5. Tradução C. P. Fernández. Cidade de Havana, Ed. Pueblo y Educación, 1989.

Historia del desarrollo de las funciones psíquicas superiores. Obras Escogidas. Vol. III. Tradução L. Kuper. Madri, Visor, 1995.

ZERBATO, A. P., LACERDA, C. B. F. Desenho infantil e aquisição de linguagem em crianças surdas: um olhar histórico-cultural. 2015. Revista Brasileira de Educação Especial. Marília, v.21, n.4, dez, 2015. p. 427-442. Disponível em: <http://www.scielo.br/scielo.php?pid=S141365382 $015000400427 \&$ script=sci_abstract\&tlng=pt $>$. Acesso em 20/01/2018. 


\section{Sobre as autoras}

Beatriz Aparecida dos Reis Turetta é Graduada em Pedagogia pelo Centro Universitário Salesiano São Paulo (2001), possui Mestrado (2006) e Doutorado (2013) em Educação pela Universidade Metodista de Piracicaba (2006). Tem experiência na área da Educação com ênfase na Educação Infantil, Ensino Superior e Pós-Graduação. Atualmente têm-se dedicado a divulgação de sua pesquisa de Pós-Doutoramento pela Universidade Federal de São Carlos e atuado em cursos de Pós-Graduação Lato-sensu. Interessa-se pela Educação Infantil e pela Educação Especial.

Cristina Broglia Feitosa de Lacerda é Graduada em Fonoaudiologia pela Universidade de São Paulo (1984), Mestre (1992) e Doutora em Educação pela Universidade Estadual de Campinas (1996). Atualmente é professor Associado I da Universidade Federal de São Carlos (UFSCar) no Curso de Licenciatura em Educação Especial e no Programa de Pós-Graduação em Educação Especial- PPGEEs. Experiência na área da Fonoaudiologia, com ênfase em Surdez, e atuação na área educacional desde 1996 com estudos desenvolvidos na perspectiva históricocultural e nos pressupostos da abordagem enunciativo-discursiva. Interesse de pesquisa: atuação do Intérprete educacional de Língua de Sinais e Educação Bilíngue de Surdos. Pós-doutorado no Centro de Pesquisa Italiano (CNR/ROMA) em 2003 e na Universidade de Barcelona em 2017. Vencedor do $1^{\circ}$ Lugar da $56^{\text {a }}$ Prêmio JABUTI área de Educação com o livro "Tenho um aluno surdo e agora?" Ed. UFSCar.

${ }^{\mathrm{i}}$ As iniciativas de pesquisa nesta unidade escolar têm recebido apoio de agências de fomento, a saber: Proc. CNPq 443756/2015-5; Proc. FAPESP 2012/17730-9.

ii Na escola de Ensino Fundamental também é oferecida a EJA para pessoas surdas que se interessem.

iii Língua de instrução é a língua utilizada pelo professor em todas as situações de ensino e interação com os alunos no cotidiano escolar.

Recebido em julho de 2018.

Aprovado em outubro de 2018. 